\title{
MANAJEMEN DATA PENDIDIKAN ANAK SECARA REAL-TIME DENGAN OPEN-SOURCE SMART REGISTER PLATFORM (OpenSRP)
}

\section{REAL TIME DATA MANAGEMENT FOR CHILDREN EDUCATION BY USING OPEN-SOURCE SMART REGISTER PLATFORM (OpenSRP)}

\author{
Sudirman* \\ *Program Studi Pendidikan Matematika, Universitas Qamarul Huda Badaruddin Bagu, Provinsi Nusa \\ Tenggara Barat, Indonesia
}

*Jl. H. Badaruddin Desa Bagu Kab. Lombok Tengah Prov. Nusa Tenggara Barat-Indonesia

\begin{tabular}{l} 
Informasi Artikel \\
\hline Article History: \\
Submission: $02 / 06 / 2021$ \\
Revised: $07 / 06 / 2021$ \\
Accepted: $15 / 06 / 2021$ \\
Kata Kunci: \\
Manajemen data; real-time; \\
pendidikan anak; OpenSRP
\end{tabular}

\section{Keywords:}

Data management; real time; child education; OpenSRP.

\section{* Korespondensi:}

Sudirman sudirman@uniqhba.ac.id

\section{Abstrak}

Di Nusa Tenggara Barat, data tersebar di berbagai sektor namun belum ada pengelolaan data secara real-time. Kami membuat tahapan proses dalam merancang sistem manajemen data tepat waktu untuk mendukung pertumbuhan, perkembangan dan pendidikan anak. Studi formatif dilakukan di Kabupaten Lombok Barat dan Kabupaten Lombok Timur secara random sampling untuk mengumpulkan informasi pada 1059 orang tua anak atau pengasuh melalui pemetaan data, wawancara mendalam, pemeriksaan dokumen, dan entri data secara langsung menggunakan Open-source Smart Register Platform (OpenSRP). Untuk memperoleh gambaran lengkap tentang pendidikan dan tumbuh kembang anak dihubungkan dalam satu platform. Penelitian ini menggunakan Open-source Smart Register Platform (OpenSRP) untuk manajemen data pendidikan menggunakan tablet $P C$ atau smartphone. Data dapat dengan mudah dimasukkan kapan saja secara tepat waktu menggunakan Enketo form. Jika infrastruktur jaringan internet belum tersedia, platform ini juga memungkinkan untuk memasukkan data secara offline dan dapat secara otomatis tersimpan pada server database ketika koneksi jaringan tersedia. Segera setelah entri data selesai platform ini menyediakan dashboard yang berisi laporan data secara real time yang dapat diakses oleh pemangku kepentingan di setiap tingkatan. Untuk menghindari penyalahgunaan data, akses tersebut juga akan dibatasi dengan sistem login yang aman. Berdasarkan studi formatif ini, OpenSRP dapat diterapkan untuk manajemen data pendidikan secara tepat waktu sesuai dengan indikator nilai rata-rata pengiriman data tepat waktu sebesar 93,39\%, kualitas dan kelengkapan data sebesar 83,94\%.

Abstract
In West Nusa Tenggara, the data is scattered in various sectors but there is
no real-time data management, we report the stages of the process in
designing a timely data management system to support children's growth,
development, and education. The formative study was conducted in West
Lombok Regency and East Lombok Regency by random sampling to collect
information on 1059 children's parents or caregivers through data
mapping, in-depth interviews, document checking, and direct data entry
using the Open Smart Register Platform (OpenSRP). To get a complete
picture of children's education and growth, they are connected in one
platform. This study introduces the Open Smart Register Platform
(OpenSRP) for educational data management using a tablet PC or


smartphone. Data can be easily entered at any time on time using the Enketo form. If the internet network infrastructure is not yet available, this platform also allows for offline data entry and can be automatically stored on the database server when a network connection is available. As soon as data entry is completed the platform provides a dashboard containing realtime data reports that can be accessed by stakeholders at every level. To avoid misuse of data, such access will also be limited by a secure login system. Based on this formative study OpenSRP can be applied for timely management of education data, refer to the average values of performance indicators where on-time submission was 93,39\%, completeness, and data quality were $83,94 \%$.

\section{PENDAHULUAN}

Banyak pekerja lapangan bidang pendidikan yang mengandalkan pencatatan kertas mengeluh bahwa penyusunan laporan bulanan dan tahunan secara manual untuk supervisor membutuhkan lebih banyak waktu daripada yang seharusnya. Selain itu, supervisor mengeluh bahwa laporan yang mereka terima dari lapangan tidak lengkap atau tidak terkompilasi dengan baik. Salah satu keuntungan beralih ke sistem pencatatan tanpa kertas adalah kemampuan untuk mengotomatisasi dan menstandarisasi pelaporan di semua tingkatan dalam sistem lapangan[1]. Data yang dimasukkan dapat disinkronkan secara otomatis dengan modul pelaporan, sehingga pekerja dapat mengakses dan menyusun laporannya kapan saja. Mereka dapat dengan mudah melacak kemajuan mereka selama satu bulan atau tahunan tanpa harus mengumpulkan data secara manual. Pengawas dan otoritas pelaporan dapat meyakini bahwa data yang dilaporkan akurat dan mencerminkan penyediaan layanan nyata dan kejadian kesehatan di lapangan. Mereka dapat dengan mudah mendeteksi anomali dengan pelaporan digital dan secara signifikan mengurangi waktu untuk menanggapi keadaan darurat, seperti wabah penyakit, saat itu terjadi[2].

Di daerah pedesaan, atau di mana pun pekerja lapangan mungkin tersebar dan sulit dijangkau, jika mereka memiliki portal web online dan dashboard untuk pemantauan kegiatan harian adalah cara yang efisien dan cerdas untuk memastikan petugas secara teratur memberikan pelayanan secara tepat waktu[3]. Melalui portal web memungkinkan login pengguna untuk memantau data pendidikan dan mencetak laporan secara digital. Supervisor di tingkat yang lebih tinggi dapat login untuk memantau petugas dan melihat penyediaan layanan mereka secara real time pada semua petugas sesuai dengan bidangnya. Portal web juga dapat mengarsipkan data backup yang bisa diakses pada waktu tertentu. Di Nusa Tenggara Barat, data pendidikan belum ada pengelolaan data secara real-time. Melalui penelitian ini penulis mengembangkan sistem manajemen data real-time yang dapat diterapkan untuk perbaikan program pendidikan dalam mendukung pertumbuhan dan perkembangan anak. Dengan adanya data pendidikan yang valid dan tersedia secara tepat waktu akan memudahkan penentu kebijakan dalam mengambil keputusan untuk mengatasi permasalahan pendidikan mengenai tumbuh kembang anak. 


\section{METODE}

Manajemen data dengan OpenSRP merupakan sistem pelacakan kumpulan data berupa perangkat lunak entri data yang dirancang untuk register pintar menggunakan tablet PC atau smartphone. OpenSRP menggunakan Enketo form untuk entri data. Studi formatif dilakukan di Kabupaten Lombok Barat dan Kabupaten Lombok Timur secara random sampling untuk mengumpulkan informasi pada 1059 orang tua anak atau pengasuh sebagai responden melalui wawancara mendalam, pemetaan data, tinjauan dokumen, dan penginputan data secara langsung di lapangan menggunakan OpenSRP.

\section{HASIL DAN PEMBAHASAN}

Penelitian ini menyediakan informasi dalam satu platform yang disebut Open-source Smart Register Platform (OpenSRP), yang akan menampung semua register pendidikan, kurikulum pendidikan dan dokumen kerja lainnya. Petugas atau staf lapangan akan memiliki akses ke sistem ini dengan memasukkan data melalui tablet atau ponsel menggunakan login dan password yang bersifat rahasia sesuai dengan kewenangan dan bidang layanan petugas[4]. Petugas lapangan pendidikan akan menggunakan tablet atau smartphone untuk pengumpulan data di lokasi penelitian terpilih pada program Pengembangan Anak Usia Dini (PAUD). Sistem ini akan memberikan komunikasi dua arah dan berbagi data antara staf lapangan yang dilatih sebagai petugas, untuk meningkatkan pelacakan dan pemantauan anak mengenai perkembangan kognitif dan fisik anak.

Untuk mendapatkan gambaran lengkap tentang tumbuh kembang anak, data dari berbagai sektor dan program telah dipetakan dan dihubungkan dalam satu Platform (Gambar 2). Penelitian ini menggunakan Open Smart Registry Platform (OpenSRP) untuk secara sistematis mengkompilasi data individu di berbagai aspek kehidupan anak, mulai dari nutrisi anak, kesehatan, pendidikan menggunakan tablet $P C[2][5]$. Data dapat dengan mudah dimasukkan kapan saja oleh penanggung jawab menggunakan formulir Enketo. Jika infrastruktur koneksi internet belum tersedia, sistem ini juga memungkinkan penyimpanan keamanan offline yang dapat secara otomatis terhubung ke server ketika koneksi jaringan tersedia. Entri data langsung akan memberikan laporan data secara real-time yang dapat diakses oleh pemangku kepentingan terkait pada tiap tingkatan untuk merespons dengan tepat. Namun, untuk menghindari penyalahgunaan data, akses tersebut juga akan dibatasi dengan sistem login yang aman[2][6]. Desain, pengelolaan, dan pemeliharaan sistem secara keseluruhan akan dikelola oleh dinas pendidikan di tingkat kabupaten. Data akan diakses dengan menggunakan login tertentu di dalam sistem untuk keperluan analisis data dan proses pelaporan. Pemanfaatan data sekunder untuk semua pemangku kepentingan atau orang lain akan dikelola dan diakses melalui satu pintu berbasis situs website dan hanya akan memberikan akses berupa data agregat yang valid dan disetujui untuk diseminasi data[7]. Proses ini akan dikelola melalui login yang aman dan memerlukan persetujuan dari petugas pendidikan tingkat Kabupaten dan Provinsi. Selain itu, setiap data yang termasuk dalam publikasi hanya akan melaporkan ringkasan atau data agregat untuk memastikan privasi dan kerahasiaan semua individu tetap terjaga.

Sistem informasi digital ini mudah dalam pengaturan dan pengoperasiannya dalam tablet PC atau smartphone dengan ketukan tombol, dan memungkinkan entri data offline di mana jaringan koneksi tidak selalu tersedia. Data disimpan dengan aman secara offline sampai perangkat memiliki koneksi jaringan lagi dan data tersebut kemudian dikirim ke server secara aman. Dengan menggunakan formulir web Enketo, pengguna dapat dengan mudah beralih dari 
satu pertanyaan ke pertanyaan berikutnya[8]. Enketo mengizinkan untuk memasukkan validasi entri data dan pertanyaan wajib dalam formulirnya[9]. Selain itu, Enketo menawarkan fitur-fitur canggih seperti kalkulasi entri data, yang berguna dalam pengisian otomatis untuk data penjumlahan agar kesalahan pengisian data dapat diminimalisir. Platform ini membuat tugas yang memakan waktu karena sebelumnya dilakukan secara manual menjadi mudah untuk diselesaikan. Sistem ini memiliki fitur berupa sortir dan filter yang dapat disesuaikan untuk mengatur ulang dan menyaring daftar nama individu yang diperlukan sesuai dengan kebutuhan kerja pengguna. Setiap register dilengkapi dengan fitur pencarian cerdas, sehingga tidak memerlukan waktu yang lama dalam pencarian nama[10]

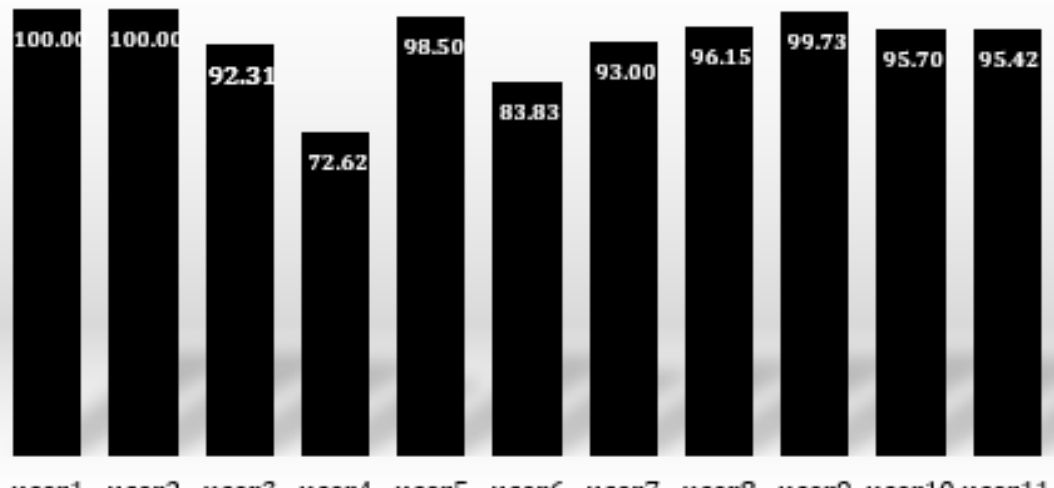

Gambar 1. Pengiriman data secara real time dengan OpenSRP
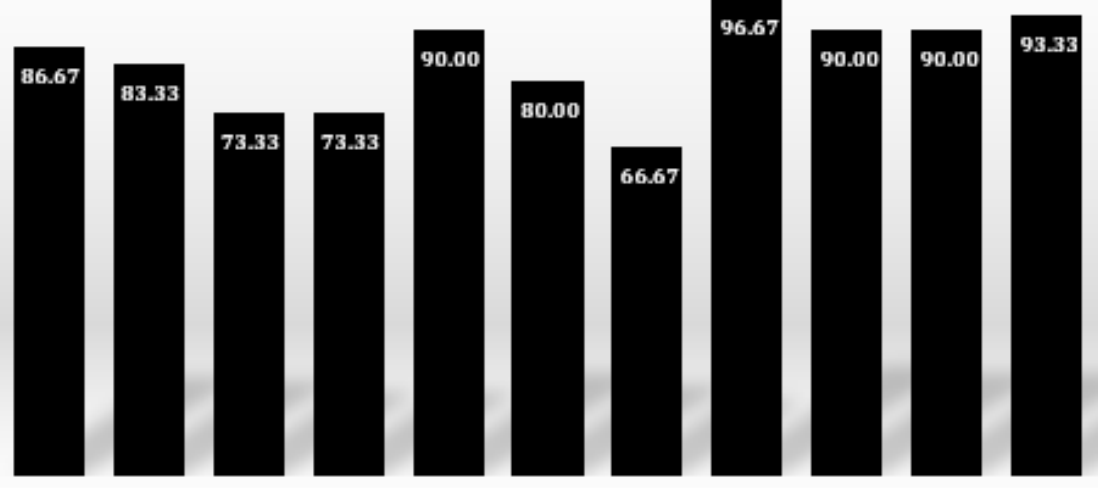

user1 user2

user4

user6 user7

user8 user9 user10 user11

Gambar 2. Kualitas dan kelengkapan data secara real time

OpenSRP memungkinkan entri data langsung di antarmuka[9][11]. Data dikumpulkan di aplikasi dengan formulir Enketo. Untuk mengurangi kesalahan pengetikan, sistim ini menggunakan algoritme pemeriksaan data untuk memeriksa konsistensi dan validitas data pada waktu entri data berlangsung[12][13]. Jika ditemukan error atau inkonsistensi maka aplikasi ini akan secara langsung minta diperbaiki. Setelah semua data masuk ke server, data di cleaning sebelum dianalisis.

Hasil analisis data dari aplikasi ini disampaikan kepada pengguna melalui kegiatan coaching. Tujuannya adalah agar tenaga kependidikan mengetahui dan memahami manfaat dari aplikasi ini dalam manajemen data terutama tentang indikator pengiriman data tepat waktu (Gambar 1) dan kualitas serta kelengkapan data (Gambar 2). Melalui coaching berbasis 
data ini mendorong dan mendukung pekerja pendidikan mengenai kepatuhan dalam penggunaan aplikasi secara online.

Data yang dimasukkan melalui formulir Enketo secara otomatis disinkronkan dengan modul pelaporan, sehingga tenaga kependidikan dapat mengakses laporan mereka kapan saja. Mereka dapat dengan mudah mengakses kemajuan pekerjaan mereka tanpa harus mengkompilasi data secara manual. Pengawas dan otoritas pelaporan yakin bahwa data yang dilaporkan akurat dan mencerminkan penyediaan layanan nyata dan keadaan pendidikan berdasarkan kondisi lapangan. Di daerah pedesaan, atau di mana pun tenaga kependidikan bertugas bahkan tersebar pada topografi yang sulit dijangkau, harus memiliki portal web dan dashboard online untuk pemantauan harian. Cara ini sangat efisien dan cerdas untuk memastikan petugas secara teratur memberikan pelayanan tepat waktu. Portal web cerdas ini memungkinkan melakukan pemantauan secara realtime walaupun tidak secara langsung melakukan pengecekan di lapangan dengan melakukan login untuk melihat perkembangan data di lapangan.

Supervisor di tingkat yang lebih tinggi dapat memantau pelayanan petugas lapangan secara real time melalui data tabulasi sesuai dengan posisi dan tugasnya. Pemanfaatan Data untuk pemangku kepentingan atau pihak lain akan diakses melalui satu pintu (berbasis website). Melalui login yang aman, pengguna akan dapat mengakses tampilan data untuk analisis dan pelaporan. Data dalam database atau dalam paket statistik akan dibatasi untuk mereka yang memiliki user dan password untuk akses laporan atau publikasi, hal ini untuk menjamin kerahasiaan semua data. Data yang dikumpulkan selama penelitian akan dilakukan secara realtime dan langsung ditransfer ke server (Gambar 1). Hanya personil yang memiliki hak akses ke data terkait untuk keperluan analisis data dan proses pelaporan. Pengecekan data yang telah dikumpulkan mengenai validitas dan konsistensi internal dilakukan secara otomatis dengan skrip (bahasa pemrograman)[14][15], skrip ini akan memudahkan dalam pengecekan inkonsistensi data dan mengingatkan supervisor mengenai potensi masalah yang memerlukan koreksi

\section{SIMPULAN}

Berdasarkan hasil penelitian ini, OpenSRP dapat diterapkan untuk manajemen data pendidikan anak secara real-time, hal ini sesuai dengan hasil analisis indikator nilai rata-rata pengiriman data tepat waktu sebesar 93,39\%, kualitas dan kelengkapan data sebesar 83,94\%. Hasil ini menyarankan penggunaan aplikasi dapat diterapkan untuk memantau kinerja secara real-time dan mengevaluasi kinerja penyedia layanan pendidikan secara rutin serta peningkatan kualitas pelayanan pendidikan secara online dan berkelanjutan

\section{DAFTAR PUSTAKA}

[1] D. Zurovac et al., "Ownership and use of mobile phones among health workers, caregivers of sick children and adult patients in Kenya: cross-sectional national survey," 2013. doi: 10.1186/1744-8603-9-20.

[2] J. D. Lisa Marsch, Sarah Lord, Behavioral Healthcare and Technology: Using Science-Based Innovations to transform practice, First Edit. New York: Oxfort University Press, 2015.

[3] World Health Organization, "Potential and Principles for Health Sector Actions to Strengthen Civil Registration and Vital Statistics Systems," Meet. Heal. Sect. Contrib. to Strength. Civ. Regist. Vital Stat. Syst., pp. 1-15, 2013, [Online]. Available: http://www.who.int/healthinfo/civil_registration/crvs_meeting_dec2013_discussionpap er.pdf. 
[4] M. Pradhan et al., "Evaluating a community-based early childhood education and development program in Indonesia: Study protocol for a pragmatic cluster randomized controlled trial with supplementary matched control group," Trials, vol. 14, no. 1, pp. 116, 2013, doi: 10.1186/1745-6215-14-259.

[5] R. E. and R. P. R.-E. Brearley, L., S. Mohamed, V. Eriyagama, Impact of Maternal and Child Health Private Expenditure on Poverty and Inequity, First Edit. Manila: Asian Development Bank, 2012.

[6] E. L. Prado et al., "Maternal multiple micronutrient supplementation and other biomedical and socioenvironmental influences on children's cognition at age 9-12 years in Indonesia: follow-up of the SUMMIT randomised trial," Lancet Glob. Heal., vol. 5, no. 2, pp. e217e228, 2017, doi: 10.1016/S2214-109X(16)30354-0.

[7] G. Mehl, "OPENSRP: Open Smart Register Platform Connecting frontline health workers to national health systems," mHEALTH Compend., vol. 5, no. June, p. 43, 2015.

[8] S. Fernandez-Rao et al., "Integrating nutrition and early child-development interventions among infants and preschoolers in rural India," Ann. N.Y. Acad. Sci, doi: $10.1111 /$ nyas. 12278 .

[9] S. Grantham-McGregor, W. Schofield, and C. Powell, "Development of severely malnourished children who received psychosocial stimulation six-year follow-up," Pediatrics, vol. 79, no. 2, pp. 247-254, 1987.

[10] Eickmann SLima AGuerra MLima MLira PHuttly SAshworth A, "Improved cognitive and motor development in a community-based intervention of psychosocial stimulation in northeast Brazil," Dev. Med. Child Neurol., vol. 45, no. 8, pp. 536-541, 2003, doi: 10.1017/S0012162203000987.

[11] C. Ca Noble, J. P. Sturgeon, M. Bwakura-Dangarembizi, P. Kelly, B. Amadi, and A. J. Prendergast, "Postdischarge interventions for children hospitalized with severe acute malnutrition: a systematic review and meta-analysis," doi: 10.1093/ajcn/nqaa359.

[12] S. Sudirman, "Pengembangan Aplikasi Untuk Pemantauan Dan Evaluasi Pendidikan Anak Usia Dini," INFOTECH J. Inform. Teknol., vol. 1, no. 2, pp. 107-115, 2020, doi: 10.37373/infotech.v1i2.61.

[13] F. E. Aboud and A. K. Yousafzai, "Global Health and Development in Early Childhood," Annu. Rev. Psychol, vol. 66, pp. 433-457, 2015, doi: 10.1146/annurev-psych-010814015128.

[14] P. T. Duke, "RANDOMISED TRIALS IN CHILD HEALTH IN 11 th Edition July 2012-June 2013," no. July 2012, 2013.

[15] S. P. Walker et al., "Inequality in early childhood: Risk and protective factors for early child development," Lancet, vol. 378, no. 9799, pp. 1325-1338, 2011, doi: 10.1016/S0140-6736(11)60555-2. 